\title{
Pavlovian conditioning and death from apparent overdose of medically prescribed morphine: A case report
}

\author{
SHEPARD SIEGEL \\ McMaster University, Hamilton, Ontario, Canada \\ and \\ DELBERT W. ELLSWORTH \\ Elizabethtown College, Elizabethtown, Pennsylvania
}

\begin{abstract}
A Pavlovian conditioning model of tolerance emphasizes the contribution of an association between predrug cues and the systemic effect of the drug to the display of tolerance. In agreement with the model, results of a recent animal experiment, as well as retrospective reports by human overdose victims, indicate that the pernicious effects of heroin are influenced by environmental cues associated with the systemic effects of the drug. The present case report describes an instance of death from apparent morphine overdose in a patient receiving the drug for medical purposes. The circumstances of this death are readily interpretable by the conditioning analysis of tolerance.
\end{abstract}

The display of tolerance to many effects of a variety of opiates is modulated by environmental cues. The contribution of such cues to tolerance has been addressed in a Pavlovian conditioning model of tolerance. The model is based on Pavlov's (1927, pp. 35-37) suggestion that the administration of a drug constitutes a conditioning trial: the conditional stimulus consists of environmental cues that are present at the time of drug administration, and the unconditional stimulus consists of drug-elicited responses. According to this interpretation, as the drug is administered with increasing frequency, with the same environmental cues signaling each pharmacological stimulation, an association is established between the cues and the central effects of the drug. This association may be demonstrated by administering an inert substance in the drug-administration environment. Conditional responses revealed in this manner are often opposite in direction to those caused by the drug effects (Siegel, 1983). Such drugcompensatory anticipatory responses attenuate the drug effects and contribute to tolerance. Accordingly, environmental signals of impending pharmacological stimulation are important because they enable the organism to make a drug-compensatory conditional response in anticipation of the drug effect. ${ }^{1}$

On the basis of this model, a failure of tolerance should occur if the drug is administered in an environment that has not previously been associated with the drug. Indeed, many studies have demonstrated such dependence of opi-

Preparation of this report was assisted by a grant from the Natural Sciences and Engineering Research Council of Canada. Requests for reprints should be addressed to Shepard Siegel, Department of Psychology, McMaster University, Hamilton, Ontario, Canada L8S 4K1. ate tolerance on environmental cues. For example, if the last of a series of morphine injections is given in the presence of cues that have not previously signaled the drug, animals and humans display less tolerance than if this injection is given in the presence of the usual drugassociated cues (see review by Siegel \& MacRae, 1984).

The conditioning model of tolerance has been elaborated to account for some instances of overdose in human heroin addicts (Siegel, 1984; Siegel, Hinson, Krank, \& McCully, 1982). Although deaths from overdoses are prevalent (Maurer \& Vogel, 1973, p. 101), the mechanisms of many of these deaths are far from clear. Some deaths result from pharmacological overdoses (see Huber, 1974), but often victims die following doses that would not be expected to be fatal for these drug-experienced, and presumably drug-tolerant, individuals (see reviews by Brecher, 1972, pp. 101-114; Reed, 1980); indeed, the victims sometimes die following self-administration of a heroin dose that was well tolerated the previous day (Government of Canada, 1973, p. 314). Some fatalities may result from a synergism between the opiate and other drugs concomitantly administered or from adulterants (especially quinine) in the illicit heroin, but many deaths do not result from such drug interactions (Brecher, 1972; Government of Canada, 1973; Reed, 1980). Thus, it has been suggested that "the term 'overdose' has served to indicate lack of understanding of the true mechanism of death in fatalities directly related to opiate abuse" (Greene, Luke, \& DuPont, 1974, p. 175). Some instances of these enigmatic failures of tolerance may be interpretable by the conditioning analysis. According to this analysis of overdose, an organism is at risk for overdose when the drug is administered in an environment that, for that 
organism, has not previously been extensively paired with the drug (and thus does not elicit the compensatory conditional pharmacological response that attenuates the effect of the drug).

Results of a recent experiment support the Pavlovian conditioning interpretation of heroin overdose (Siegel et al., 1982). Rats injected with high doses of heroin in the same environment as that previously associated with the drug were more likely to survive than rats with the identical pharmacological history receiving the final drug administration in an alternative environment.

Interviews with drug addicts who survived a heroin overdose similarly indicate a role for drug-associated environmental cues in opiate overdose (Siegel, 1984). The majority of respondents reported that, on the occasion of the overdose, the drug was administered in the context of unusual environmental cues.

We report here a case of apparent morphine overdose in a patient receiving the drug for medical purposes. The circumstances of this overdose are readily interpretable by a conditioning analysis, and they suggest that unanticipated overdoses may occur when a drug, used for therapeutic purposes, is administered in the context of environmental cues not previously associated with the drug.

\section{BACKGROUND}

The victim of the apparent morphine overdose was suffering from advanced pancreatic cancer. Either one of the patient's two sons regularly administered morphine, in accordance with the procedures and dosage levels specified by the patient's physician. The fatal dose of morphine was administered by one son, N. E., who was 17 years old at the time.

About 2 years after his father's death, N. E. was a student in an undergraduate psychology class, in which the Pavlovian conditioning analysis of drug tolerance was discussed. Realizing the applicability of the model to his father's death, N. E. discussed the matter with the instructor.

Unfortunately, many details concerning the occasion of the patient's overdose are not accessible, and some important information was forgotten over the 2-year period between the patient's death and N. E.'s insight into the potential role of pharmacological conditioning in the death. Nevertheless, there is enough information to suspect that N. E.'s interpretation of the event as another instance of exacerbation of a drug effect by environmental alteration may be correct.

\section{THE OVERDOSE}

The patient was being attended at home. His condition was obviously very poor, as N. E. recalled that his father had lost 100 lbs body weight over the course of the disease. The patient received a morphine injection four times per day (at 6-h intervals). The injections had been given for 4 weeks. There is no documentation available to in- dicate the dosage of morphine that N. E. was administering, and N. E. cannot recall this information. He does remember, however, that the dose was being gradually increased over the period that he was administering the drug to his father. Typically, the preparation of the injection was observed by both sons to preclude the possibility of a mistake.

The patient's condition was such that he stayed in his bedroom, which was dimly lit and contained much hospital-type apparatus necessary for his care. The morphine had always been injected in this environment. For some reason, on the day that the overdose occurred, the patient had dragged himself out of the bedroom to the living room. The living room was brightly lit and apparently different in many ways from the bedroom/sickroom. The patient, discovered in the living room by N. E., appeared to be in considerable pain. Inasmuch as it was time for his father's scheduled morphine injection, N. E. injected the drug while his father was in the living room. He had never administered the morphine in this environment before. The son quickly noticed that his father's reaction to this injection was atypical: his pupils became unusually small, and his breathing became very shallow.

His father's response to this injection in the living room alarmed N. E., and N. E. called his father's physician. The physician instructed N. E., by telephone, to evaluate some indices of his father's status. (Unfortunately, N. E. cannot now recall, in any detail, the type of information he provided to the physician.) Based on the information supplied by the son, the physician suggested that his father had suffered an overdose of morphine. The father died some hours later.

In view of the patient's condition, there was no postmortem examination to ascertain the potential role of morphine in his death. The evidence that he did die from an overdose is based entirely on his reaction to the final morphine administration, and the physician's interpretation of the symptoms as described in his telephone conversation with N. E. at the time of the event. Although N. E. maintains that he is confident that he prepared the injection in the usual manner, he remained confused and guilty about his role in his father's death. This reaction was substantially ameliorated when N. E. learned about the conditioning analysis of tolerance and the relevance of the model to opiate overdose.

\section{DISCUSSION}

Results of an animal experiment concerning heroin overdose indicated that "rats that received the potentially lethal dose in the context of cues previously associated with sublethal doses were more likely to survive than animals that received the dose in the context of cues not previously associated with the drug' (Siegel et al., 1982, p. 437). A similar conclusion was reached following interviews with human overdose victims: "a failure of tolerance, following drug administration in the context of cues not previously associated with the drug, may contribute 
to some occurrences of heroin overdose"' (Siegel, 1984, p. 429). Based on the present case report, it is possible that some instances of death among users of medically prescribed opiates may have a similar mechanism.

Of course, there are a variety of possible explanations for this very sick patient's death. Indeed, it appears that it is often very difficult to predict morphine kinetics in patients suffering from several types of cancer, including pancreatic cancer (Sawe, Dahlstrom, Paalzow, \& Rane, 1981). However, the available evidence of the symptoms immediately preceding death strongly implicate morphine overdose, and the circumstances of the death are congenial with a Pavlovian conditioning interpretation of this overdose. The patient's shallow breathing and constricted pupils, recalled by N. E., are classic symptoms of opiate overdose (Jaffe \& Martin, 1985). The physician's conclusion, based on the information provided by N. E., further suggests that the patient's reaction to the final morphine injection was extreme. The fact that $\mathrm{N}$. E. states that he was always assiduous in preparing the morphine (including the preparation on the occasion of the apparent overdose) suggests that there was nothing unusual about the drug dosage when his father died.

It may be estimated that N. E.'s father had received over 100 prior morphine injections, each of which occurred in the bedroom. It appears that the injection in the living room, an environment not previously associated with the systemic effects of the drug, elicited an excessive, and ul imately fatal, response. The circumstances of the overdose related by N. E. are very similar to the circumstances favoring heroin overdose, as elucidated by experimental studies with rats (Siegel et al., 1982) and by interviews with drug addicts who were hospitalized for heroin overdoses (Siegel, 1984). That is, such overdoses are especially likely if the drug is administered in the context of cues not previously associated with the drug. According to the conditioning model of tolerance, such circumstances of drug administration favor exaggerated responsivity because the drug effect is not attenuated by the pharmacological conditional compensatory response that is elicited by the usual predrug cues.

The contribution of environmental cues to this patient's death would be clearer if more information were available. The long interval between the death and N. E.'s insight into the relevance of the conditioning analysis of tolerance to the death makes it difficult to reconstruct some important cetails. Of course, the emotional circumstances surrounding $\mathrm{N}$. E.'s father's terminal illness and death are also not conducive to recall. As might be imagined, the event was very distressing to N. E., and he is to be commended for suffering through a reconstruction of his father's death to ascertain the relevance of the environmental alteration on the occasion of the final morphine administration.

\section{REFERENCES}

BAKER, T. B., \& TIFFANY, S. T. (1985). Morphine tolerance as habituation. Psychological Review, 92, 78-108.

BRECHER, E. M. (1972). Licit and illicit drugs. Boston: Little, Brown. GOVERNMENT OF CANADA. (1973). Final report of the commission of inquiry into the nonmedical use of drugs. Ottawa: Information Canada.

GreENE, M. H., LUKE, J. L., \& DUPoNT, R. L. (1974). Opiate "'overdose" deaths in the District of Columbia: I. Heroin-related fatalities. Medical Annals of the District of Columbia, 43, 175-181.

HUBER, D. H. (1974). Heroin deaths-Mystery or overdose? Journal of the American Medical Association, 229, 689-690.

JAFFE, J. H., \& MARTIN, W. R. (1985). Opioid analgesics and antagonists. In A. G. Gilman, L. S. Goodman, T. W. Rall, \& F. Murad (Eds.), The pharmacological basis of therapeutics (7th ed., pp. 491531). New York: Macmillan.

MAURER, D., \& VoGEL, V. H. (1973). Narcotics and narcotic addiction. Springfield, IL: Thomas.

Pavlov, I. P. (1927). Conditioned reflexes (G. V. Anrep, Trans.). London: Oxford University Press.

REED, T. (1980). Challenging some "common wisdom" on drug abuse. International Journal of the Addictions, 15, 359-373.

Sawe, J., Dahlstrom, B., Paalzow, L., \& Rane, A. (1981). Morphine kinetics in cancer patients. Clinical Pharmacology \& Therapeutics, 30, 629-635.

Siegel, S. (1982). Pharmacological habituation and learning. In M. L. Commons, R. J. Herrnstein, \& A. R. Wagner (Eds.), The quantitative analysis of behavior: Acquisition (Vol. 3, pp. 288-305). Cambridge, MA: Ballinger.

SiEgEL, S. (1983). Classical conditioning, drug tolerance, and drug dependence. In Y. Israel, F. B. Glaser, H. Kalant, R. E. Popham, W. Schmidt, \& R. E. Smart, (Eds.), Research advances in alcohol and drug problems (Vol. 7, pp. 207-246). New York: Plenum Press.

SIEGEL, S. (1984). Pavlovian conditioning and heroin overdose: Reports by overdose victims. Bulletin of the Psychonomic Society, 22, 428-430.

Siegel, S., Hinson, R. E., KranK, M. D., \& MCCully, J. (1982). Heroin "overdose" death: The contribution of drug-associated environmental cues. Science, 216, 436-437.

Siegel, S., \& MACRAE, J. (1984). Environmental specificity of tolerance. Trends in NeuroSciences, 7, 140-142.

\section{NOTE}

1. It should be noted that there are theoretical frameworks, other than that emphasizing drug-compensatory conditional responses, that have been used to integrate Pavlovian conditioning and drug tolerance (e.g., Baker \& Tiffany, 1985). A full discussion of these approaches is beyond the scope of this paper (but see Siegel, 1982; Siegel \& MacRae, 1984). However, these alternative associative accounts of tolerance make the same predictions concerning the effect of environmental alteration on the display of tolerance as does the compensatory conditional response account.

(Manuscript received for publication April 17, 1986.) 